\title{
PERCEPTION AND USE OF CONTRACEPTIVES AMONG WOMEN \\ IN FARMING HOUSEHOLDS OF RURAL OYO
}

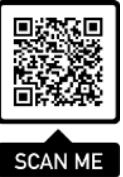

\section{Chuks ONYEKA IDIAYE (iD) $1 *$ \\ Isaac BUSAYO OLUWATAYO (iD ${ }^{2}$ \\ Taiwo OLUWASEUN DISU (iD ${ }^{3}$}

\author{
1 University of Ibadan, Faculty of Agriculture, Department of Agricultural Economics, chuksidiaye@yahoo.com *Correspondent \\ Author. \\ 2 University of Venda, Department of Agricultural Economics and Agribusiness, isaacoluwatayo@yahoo.com \\ 3 University of Ibadan, Faculty of Agriculture, Department of Agricultural Economics, taiwodisu2@gmail.com
}

\section{Article history:}

Submission 12 August 2021

Revision 10 October 2021

Accepted 05 December 2021

Available online 31 December 2021

\section{Keywords: \\ Contraception, \\ Farming Households, \\ Nigeria, \\ Perception,}

Rural area.

DOI:

https://doi.org/10.32936/pssj.v5i3.267

\begin{abstract}
A b s t r a c t
The objective of this study was to investigate the extent and perception of contraceptive use among women from farming households in Oyo state, Nigeria. Descriptive statistics were used in profiling the socioeconomic characteristics of respondents, a multinomial logistic model was used to estimate the determinants of contraceptive usage, while the Likert scale was used to measure their perception towards the use of contraceptives. A total of 150 women were interviewed using a structured questionnaire. The results obtained indicated that while only $27 \%$ of the women were aware of contraceptives, $23 \%$ of them had used them. Cost was the most important consideration among the women for choosing a method as indicated by $41 \%$ of them. Further, among those who had not used any contraceptive, traditional and religious beliefs were their major considerations. The regression analysis showed formal education to be a significant factor (at $\alpha 0.05$ ) that increased the probability of women embracing contraception. Perception towards contraceptives among women in rural Oyo State, Nigeria was seen to be generally positive, although convenience of the methods (mean score 1.49) and side effects (means score 1.35) were considered to be drawbacks It was recommended that more awareness needed to be created on birth control along with the introduction of modern methods of contraception with fewer side effects. Also, family planning interventions in Nigeria should be made context-specific and culturally appealing so as to increase their acceptability in rural farming communities.
\end{abstract}

\section{Introduction}

Developing countries often experience huge population growth that is partly attributable to high birth rates coupled with lowered death rates along with low adoption of contraception (Oyedokun, 2007). Sub-Saharan Africa (SSA) has one of the highest population growth rates in the world at $2.8 \%$ (USAID/HPI, 2007). Specifically, Ethiopia has a fertility rate of 5.4 births per woman (Ethiopia Demographic and Health survey, 2005; Population Reference Bureau, 2007) while it is 7births per women in Niger and5.3in Nigeria (NDHS 2018). High population growth puts enormous pressure on health, education and other public goods and infrastructure and as such can be an impediment in the reduction of child mortality, improvement of maternal health, attainment of universal primary education, environmental sustainability and combating HIV/AIDS, malaria and other diseases as part of the Sustainable Development Goals (SDG) (Health Policy Initiative, 2007). Furthermore, highly populated societies are known to experience endemic poverty, inadequate education and large families that affect access to basic health services including family planning. Womenfolk in rural areas show the highest levels of unmet needs for family planning, estimated at 33 per cent as against only 17 per cent in higher income groups (USAID/HPI, 2007).

Globally, birth control is employed as a way of addressing the reproductive health needs of society, as well as mitigating population explosion (Shrestha et al., 2000). Birth control is a practice by which a couple determine the spacing of births 
through the use of contraception. It is estimated that over 200 million women in developing countries desire to delay pregnancy or stop childbearing entirely, however they often use traditional methods of contraception which have proven to be less successful or use none at all due to lack of access or barriers to their use of contraception (Westoff, 2012).

The global increase in the use of contraceptives has afforded families the opportunity to choose the number and spacing of their children with attendant lifesaving advantages. However, despite the obvious merits, contraception and other modern family planning methods are still poorly adopted in the world's poorest and most populous societies. The significance of providing birth control, while recognizing the rights of individuals to make informed choices, is considered part of a wide-ranging set of services needed to fill the reproductive health needs of individuals and tackle more expansive development issues (Westoff and Cross, 2006). There, however, still exists a gap between the understanding and adoption of contraceptive use (Charles and Ann 2000). Insufficient understanding of family planning methods as well as incomplete or wrong information about their use or where to obtain them are some of the major factors responsible for the low acceptance of family planning in many developing countries including Nigeria (Gilliam et al., 2004; Onwudiegwu 2002; Orji and Castle, 2003). According to NDHS 2018, only $17 \%$ of married women of reproductive age use contraceptives in Nigeria. The United Nations estimate that Nigeria will attain a population of about 440 million persons by the end of the year 2050 making Nigeria globally the third most populated nation. Therefore, for its current per capita income to be maintained, economic output from agriculture and industry along with healthcare delivery and the provision of other social services would be required to double across the next 30 years. These estimates mean that rapidly increasing population would continue to be a matter of paramount concern for Nigeria for the foreseeable future.

Currently Nigeria has the largest population of any country in Africa, with more than 160 million people, at an annual population growth rate of $3 \%$ and a fertility rate of 5.7 lifetime births per woman (NDHS, 2018). Within the rural population, the growth rate was 1.31 as at 2011. These rural areas are usually characterized by high poverty levels, low levels of education and large household sizes. Since rural women are often less educated than their urban counterparts, often resulting in deficient knowledge of family planning services, the adoption of contraception is expected to be low relative to national estimates of 46 per cent. It is pertinent to note, however, that any potential reduction in population growth rate in Nigeria (and sub-Saharan Africa) will be based largely on the balance between the demand for smaller families and the supply of birth control technology (NDHS, 2018) especially in the rural areas.

As a consequence of this and other major demographic and health concerns, a national population policy was effected which was designed to achieve a reduction in the birth rate through voluntary birth control methods attuned to the nation's economic and social goals. Among the methods propagated under this policy were mass media campaigns. Studies have shown that exposure to a mass media family planning campaigns increases contraceptive use among households (Odimegwu et al, 1997; Westoff and Rodriguez, 1995). Overall, 20 per cent of currently married women have inadequate access to family planning - 15 per cent to child-spacing and 5 percent to child-limiting. It has been opined that were this gap to be bridged, the rate of contraceptive use for any of the methods would increase from 15 to 35 per cent and there would be an improvement in their welfare status in Nigeria (NDHS, 2018).

According to World Bank (2003), the adoption of family planning services is a critical subject for a developing nation which Nigeria is. Thus, family planning advocacy in countries like Nigeria with high birth rates especially in the rural areas has the capacity to reduce poverty and enhance their welfare status. This will contribute greatly to the empowerment of womenfolk, attainment of universal primary education and long term environmental sustainability (Daar, 2017). Hawkins et al. (1995) showed that family planning services confer many economic advantages to households, the country and the world at large. Further, family planning contributes to reduction in population growth, poverty reduction, welfare improvement and preservation of the environment as well as reducing demand for public goods and services (Rele et al., 2019).

This paper therefore sought to investigate the extent, perception and determinants of contraceptive use among rural women from farming households in Ido local government area of Oyo state, Nigeria.

\section{Methodology}

\subsection{The study area}

This study was conducted in Ido Local Government Area of Oyo state. Oyo state is an inland state in south-western Nigeria with its capital at Ibadan. It is bounded by Kwara state in the north, in the east by Osun state, in the south by Ogun state and in the west partly by Ogun state and partly by the republic of Benin. Ido Local Government Area of Oyo state has an area of 986 square kilometres and a population of 103,261 according to the 2006 population and housing census. 


\subsection{Data Collection/sampling Procedure}

Respondents were obtained through a random selection of farming households within the LGA. Structured questionnaires were administered on the wives in each household. A sample size of 150 respondents was used. Data collection started in December 2015 and was concluded in March 2016.

\subsection{Methods of Data Analysis}

Descriptive statistics were used in profiling the socioeconomic characteristics of the respondents as well as their contraceptive awareness and use.

A multinomial logistic regression was estimated to examine the determinants of rural women's choice of contraceptive usage. This method has the advantage of permitting regression against more than two categories of the dependent variable, thereby allowing the determination of choice probabilities for each category (Gujarati, 2004; Deressa et al, 2009).

Given a dependent variable $Y_{i}$ representing the decision of a respondent to use (or otherwise) contraception (where $\mathrm{i}=1,2, \ldots$ . j), the multinomial logistic model used incorporates three categories of the dependent variable: (i) those who have used contraception and never stopped (ii) those who have used contraception and stopped and (iii) those who have never used contraception. On the other hand, the vector $\mathbf{X}$ is a set of explanatory variables which influence the choice made ( $Y_{i}$ ). The model, therefore estimates the effects of changes in the covariates of $\mathbf{X}$ on the response probabilities as follows:

$$
\mathrm{P}\left(Y_{i}=\frac{\mathrm{j}}{\mathbf{X}}\right)=\frac{\operatorname{Exp}\left(\mathbf{X} \beta_{k}\right)}{\left(1+\sum_{h=1} \operatorname{Exp}\left(\mathbf{X} \beta_{h}\right)\right)}
$$

Where $\beta_{k}$ represents the coefficients of the covariates of $\mathbf{X}$ to be estimated (where $\mathrm{k}=1 \ldots \mathrm{j}$ )

The explanatory variables included in the model are:

$\mathrm{X} 1$ = Age of the respondent (in years)

$\mathrm{X} 2=$ Religion of the respondent (Christian $=1,0=$ Muslim $)$

$\mathrm{X} 3$ = Household size (in number)

$\mathrm{X} 4$ = Number of years of formal education (in years)

$\mathrm{X} 5=$ Number of years of formal education of partner (in years)

$\mathrm{X} 6=$ Number of female children 17years or younger in the household (in numbers)

$\mathrm{X} 7=$ Number of male children 17 years or younger in the household (in numbers)
$\mathrm{X} 8=$ Primary occupation in agriculture (Yes $=1,0$ otherwise)

$\mathrm{X} 9=$ Social group membership of the respondent $(\mathrm{Yes}=1,0$ otherwise)

The Likert scale was used to measure the perception of the respondents regarding the use of contraceptives. It was measured by asking the respondents to rate in qualitative terms their perception using a four point Likert type scale ranging from "very satisfied" (3), "satisfied" (2), "fairly satisfied" (1) to "not satisfied" $(0)$. The mean satisfaction level was obtained by adding the Likert scale points (i.e. $0+1+2+3$ ) to obtain a score of 6 which was divided by four to get a mean score of 1.5. The respondents' mean score was obtained on each index of contraceptive use measured. Any index with a mean score greater than or equal to 1.5 was regarded as satisfactory while one with a mean score less than 1.5 was considered to be unsatisfactory.

\subsection{Limitations of the Study}

A few challenges were encountered while collecting data for this study including the following:

- Outright refusal of some potential respondents to be interviewed, thereby limiting the sample size.

- Unwillingness of some of the rural women to disclose information regarding contraception which they considered too personal.

- Limited funds, given the fact that the study was entirely self-sponsored.

\section{Results and Discussion}

\subsection{Socio-economic Characteristics of Respondents}

Table 1 shows that $96 \%$ of the rural women surveyed were 49 years of age or below with a mean age of 34 years. This showed that the women farmers in the study area were mostly within their child-bearing years. Also, most of them (90.7\%) were married and had some form of formal education (60\%).Education can influence rural women's use, as well as choice, of contraceptives and also determine their understanding of the various methods available. On the average, the respondents had 4.6 years of formal education. Households in the study area were modest, with an average of 5 persons per household. Furthermore, farming was the primary occupation of most $(83.3 \%)$ of the sampled women, while $34 \%$ of them practised mixed farming. Most $(90.0 \%)$ of the respondents did not belong to any social groups which could be a factor in their level of contraceptive adoption as information can be passed across via social groups 
Table 1. Socioeconomic characteristics of rural women $(n=150)$

\begin{tabular}{|c|c|c|c|c|c|}
\hline Socioeconomic Characteristic & Percentage & Socioeconomic Characteristic & Percentage & Socioeconomic Characteristic & Percentage \\
\hline Age & & Household size & & Do you belong to any social group & \\
\hline $20-29$ & 29.3 & $2-4$ & 36 & Yes & 10 \\
\hline $30-39$ & 46.7 & $5-7$ & 57.3 & No & 90 \\
\hline $40-49$ & 20.0 & $8-10$ & 4 & Level of monthly food expenditure & \\
\hline $50-59$ & 4.0 & $11-13$ & 2.7 & Less than or equal to $\mathrm{N} 1,000$ & 18 \\
\hline Mean $=34.4$, Standard deviation $=7.3$ & & Mean $=5.3$, Standard deviation $=1.8$ & & $\mathrm{~N} 1,001-\mathrm{N} 5,000$ & 39.3 \\
\hline Marital status & & Number of males & & $\mathrm{N} 5,001-\mathrm{N} 10,000$ & 18.7 \\
\hline Single & 1.3 & $1-3$ & 80.7 & Greater than N10,000 & 24 \\
\hline Married & 90.7 & $4-6$ & 14.7 & Level of monthly non-food expenditur & \\
\hline Divorced & 4.7 & $7-9$ & 3.3 & Less than or equal to $\mathrm{N} 1,000$ & 27.3 \\
\hline Widowed & 3.3 & Number of females & & $\mathrm{N} 1,001-\mathrm{N} 5,000$ & 36.7 \\
\hline Level of Education & & $1-3$ & 79.6 & $\mathrm{~N} 5,001-\mathrm{N} 10,000$ & 19.3 \\
\hline No formal education & 40 & $4-6$ & 20.4 & Greater than $N 10,000$ & 16.7 \\
\hline Primary & 36.7 & Is farming your primary occupation? & & & \\
\hline Secondary & 23.3 & Yes & 83.3 & & \\
\hline Number of years of formal education & & No & 16.7 & & \\
\hline $1-4$ & 17.9 & If yes, what type of farming & & & \\
\hline $5-8$ & 61.5 & Crop farming & 29.3 & & \\
\hline $9-12$ & 19.2 & Livestock farming & 28.4 & & \\
\hline $13-16$ & 1.4 & Mixed farming & 38.0 & & \\
\hline Mean $=4.6, \quad$ Standard deviation $=3.9$ & & Others & 4.3 & & \\
\hline
\end{tabular}

Source: Authors' computation from survey data

\subsection{Awareness and usage of Contraceptives}

\section{Methods}

Table 2 reveals that $27 \%$ of the respondents had knowledge of contraceptives while $73 \%$ had never heard about them. Of the 41 respondents who were aware of contraceptives, most $(68.3 \%)$ indicated that abstinence, condoms and withdrawal were the available methods they knew about. The table further revealed that mass media (television, newspapers and radio) were the main source of information about contraceptives for the respondents $(60 \%)$ while health centres were also an important source of information (24\%). Most of the respondents (77.3\%) had not used some form of contraception while $22.7 \%$ had. Similarly, OyeAdeniran et al., (2006) showed good knowledge and awareness did not always translate to a high prevalence of use of contraception. The use of condoms (41\%) was the most common method among the respondents who employed contraception. This finding is similar to that of Abiodun and Balogun (2009) who also found that the use of condoms was the most commonly employed method of contraception (69\%) in Ilorin, Kwara State. Furthermore, the decision on which method of contraception to use was mainly based on the low cost of the method as indicated by $41 \%$ of the women interviewed, while partner's decision was the second most important consideration $(30 \%)$ and $41 \%$ of the women had even had to stop the use of contraception at some point due to their partner's perception. Over $75 \%$ of the women interviewed who had never used contraception cited traditional or religious beliefs as their reasons for not using any method.

Table 2. Awareness and use of contraceptive methods

\begin{tabular}{|c|c|c|}
\hline & Frequency & Percentage \\
\hline \multicolumn{3}{|c|}{ Have you ever heard of contraceptive methods $(n=150)$} \\
\hline Yes & 41 & 27.2 \\
\hline No & 109 & 72.8 \\
\hline \multicolumn{3}{|l|}{ Available methods known $(n=41)$} \\
\hline Oral, condom, withdrawal & 11 & 26.8 \\
\hline Abstinence, condom, withdrawal & 28 & 68.3 \\
\hline Oral, abstinence, implant & 1 & 2.4 \\
\hline Oral, abstinence, condom & 1 & 2.4 \\
\hline \multicolumn{3}{|c|}{ Sources of information about methods $(n=41)$} \\
\hline Health centres & 10 & 24 \\
\hline Television & 9 & 21.9 \\
\hline Newspaper & 8 & 18.4 \\
\hline Radio & 8 & 20.1 \\
\hline
\end{tabular}


Have you ever used any contraceptive method $(n=150)$

Yes

No

Methods used $(\mathbf{n}=34)$

Oral drugs

Withdrawal

Uterine implant

Condom

Withdrawal, condom

Why did you choose the method $(n=34)$

It is cheap

Few side effects

Partner's decision

Others

Have you ever had any reason to stop using this method $(n=34)$

Method is too expensive

I experienced health problems

Partner didn't like the method

No reason

Reason for non - usage $(\mathbf{n}=116)$

Methods have side effects

\subsection{Determinants of Contraceptive Usage}

The results of the multinomial logistic regression model on the determinants of contraceptive usage are presented in Table 3. Respondents that used contraceptives but stopped are the base category. The results revealed that formal education of a respondent was positively and significantly related to the continuous usage of contraception, implying that the more educated the respondents were, the more likely they were to continuously use contraception. This can be connected to their increased awareness of the benefits of contraception due to their education as opined by Gidado (2012). Similar positive relationships between contraceptive usage and educational attainment were found by Kaggwa et al., (2008).

Contrary to common opinion, the results in Table 3 showed that religion is not a significant determinant of contraceptive usage among the rural women. Also, those with more female children, 17 years of age or younger were more likely to never use contraception. This is not surprising given the fact that past studies in Nigeria has shown that women are less likely to use contraceptives during their early reproductive years as depicted in the study by Ebigbola and Ogunjuyigbe (1998) and Oyedokun (2007).

Table 3. Determinants of contraceptive usage

\begin{tabular}{lccc}
\hline Explanatory variables & $\begin{array}{c}\text { Used and never stopped } \\
\text { (P-value) }\end{array}$ & $\begin{array}{c}\text { Never used } \\
\text { (P-value) }\end{array}$ & $\begin{array}{c}\text { Marginal } \\
\text { effects }\end{array}$ \\
\hline \multirow{2}{*}{ Age } & -0.376 & 0.0149 & 0.004 \\
& $(0.490)$ & $(0.814)$ & \\
Religion & -0.120 & -1.494 & -0.068 \\
& $(0.926)$ & $(0.361)$ & \\
Household size & 0.0953 & -0.227 & 0.008 \\
Formal education & $(0.776)$ & $(0.427)$ & \\
\hline
\end{tabular}




\begin{tabular}{|c|c|c|c|}
\hline & $(0.010)$ & $(0.297)$ & \\
\hline Formal education of partner & $\begin{array}{c}-0.222 * * \\
(0.036)\end{array}$ & $\begin{array}{c}0.081 \\
(0.608)\end{array}$ & -0.019 \\
\hline $\begin{array}{l}\text { Number of female children } \\
(\leq 17 \text { years })\end{array}$ & $\begin{array}{c}0.118 \\
(0.787)\end{array}$ & $\begin{array}{l}-0.434 \\
(0.412)\end{array}$ & 0.011 \\
\hline $\begin{array}{l}\text { Number of male children } \\
(\leq 17 \text { years })\end{array}$ & $\begin{array}{c}0.442788 \\
(0.932)\end{array}$ & $\begin{array}{l}0.701 * \\
(0.098)\end{array}$ & -0.000 \\
\hline Primary occupation & $\begin{array}{l}-0.002 \\
(0.999)\end{array}$ & $\begin{array}{c}0.330 \\
(0.772)\end{array}$ & -0.002 \\
\hline Social group membership & $\begin{array}{r}1.550 \\
(0.279)\end{array}$ & $\begin{array}{c}1.891 \\
(0.148)\end{array}$ & 0.121 \\
\hline Choice of usage & $\begin{array}{l}-0.242 \\
(0.725)\end{array}$ & $\begin{array}{c}16.81 \\
(0.990)\end{array}$ & -0.117 \\
\hline Constant & $\begin{array}{l}-2.275 \\
(0.381)\end{array}$ & $\begin{array}{l}-18.588 \\
(0.988)\end{array}$ & \\
\hline Log likelihood & -67.362 & & \\
\hline Pseudo R square & 0.233 & & \\
\hline L-R chi square & 41.46 & & \\
\hline Number of observations & 150 & & \\
\hline Base category & Used and stopped using & & \\
\hline
\end{tabular}

\subsection{Perception of the use of Contraceptive Methods}

Table 4 shows that the respondents were satisfied with most of the indices of contraceptive usage. The result indicated that the rural women interviewed were only dissatisfied with the level of convenience of the use of contraceptives as well as the side effects some of them experienced. The role of community health workers in creating awareness on birth control received the highest mean score (2.22), indicating that there were marked efforts being made to spread awareness on contraception in the area. Also, the respondents generally agreed that the use of contraceptives was effective in birth control as indicated by its high mean score (2.03). These results imply that, overall, rural women could be said to be positively disposed to contraception.

Table 4. Perception of respondents of the use of contraceptive methods

\begin{tabular}{clc}
\hline S/N & Indices of contraceptive use & Mean Score \\
\hline 1. & Level of convenience & 1.49 \\
2. & Few side effects & 1.35 \\
3. & Birth control efficacy & $2.04^{*}$ \\
4. & Accessibility to contraceptive methods & $1.95^{*}$ \\
5. & Providers' attitude & $1.91^{*}$ \\
6. & Level of confidence in the use of the methods & $1.80^{*}$ \\
7. & Cost of getting the methods & $2.01^{*}$ \\
8. & Professional competence of the provider & $1.89^{*}$ \\
9. & Role of community health workers in creating awareness on birth control & $2.22^{*}$ \\
\hline
\end{tabular}

Source: Authors' computation from survey data

* Indicates mean scores greater than the Likert scale mean (1.5)

\section{Conclusions and Recommendations}

This study has revealed that, although the level of contraceptive usage among rural women from farming households in Oyo State, Nigeria is relatively low, the general perception towards it, among those who have used it, is positive and this can be attributed largely to the efforts of community health workers in spreading awareness of the benefits of contraception as well as the cheap sources of contraceptives made accessible to rural women. Also, education of women can significantly increase the likelihood that they will accept contraception. However, more efforts are still needed to change the perception of most rural families on contraception as these still hold on to traditional beliefs and customs which forbid its use. Based on the findings of this study, the following recommendations are made: 
More awareness should be created by the governments at the state and local government levels on birth control measures especially through mass media which has been shown in this study to be the most important source of information on contraception. Studies such as Abiodun et al (2009) and Oye-Adeniran et al (2000) have shown that mass media is a good means to disseminate information on contraception in order to create more awareness. This becomes even more important given the fact that, as both studies showed, efforts in this regard in Nigeria have not yet translated into strong prevalence of use of contraception. Rather, there has been a high level of sexual activity corresponding with a low contraceptive prevalence with the average age of sexual debut in many studies ranging between 12 and 20 years, with a mean age of 16 years (Oye - Adeniran et al., 2005, Okpani et al., 2000).

More modern methods of contraception with fewer side effects such as subcutaneous implants can be introduced to rural women so as to reduce or eliminate biases against contraceptive use which are based on the side effects of other methods. Umoh and Abah (2011) similarly revealed that fear of side effects and previous side effects experienced were among the major factors that caused unwillingness to use contraception among in Southsouth Nigeria.

Family planning interventions in Nigeria should also be made context-specific and culturally appealing so as to increase their acceptability among rural communities. As Etokidem et al (2017) showed, cultural factors play a major role in the decision of households to use (or not) contraceptives. Therefore, birth control education can be incorporated into farming programed/schemes targeted at rural farming communities in order to increase their appeal so as to ensure greater uptake of family planning.

\section{References}

1. Abiodun, O.M., \& Balogun, O.R. (2009). Sexual activity and contraceptive use among young female students of tertiary educational institution in Ilorin, Nigeria. Journal of Contraception, 79(2): 146-149. https://doi.org/10.1016/j.contraception.2008.08.002

2. Charles, W. \& Ann, P. (2000). Alternative measure for unmet need for family planning in developing countries. International Family Planning Perspective, 7(4):126-135. https://doi.org/10.2307/2947843

3. Daar, J. (2017-02-21). The Reproductive Revolution. In The New Eugenics: Selective Breeding in an Era of Reproductive Technologies. Yale University Press. Retrieved 21 Oct. 2021, from https://www.universitypressscholarship.com/view/10
$.12987 /$ yale/9780300137156.001.0001/upso-

9780300137156-chapter-1

4. Deressa, T., Hossen, R., Alemu, T., Yesuf, M. \& Ringle, C. (2008). Analyzing the determinants of farmers' change of adaptation measure and perception climate change in the Nile basin of Ethiopia. IFPRI Discussion Paper No. 00798, Washington. Analyzing the Determinants of Farmers' Choice of Adaptation Methods and Perceptions of Climate Change in the Nile Basin of Ethiopia (core.ac.uk).

5. Ebigbola, J.A., \& Ogunjuyigbe, P.O. (1998). Contraceptive Knowledge and Practice by Women Attending Antenatal Clinic in Nigeria. Ife Social Sciences Review, 15(1): 20-29. Contraceptive knowledge and practice by women attending antenatal clinic in Nigeria. | Semantic Scholar.

6. Ethiopia Demographic and Health Survey (EDHS) Report (2005). Central Statistical Authority and ORC Macro, Ethiopia Demographic and Health Survey 2005, Addis Ababa, Ethiopia and Calverton, Maryland, USA.

7. Etokidem, A.J., Ndifon, W., Etowa, J., \& Asuquo, E.F. (2017). Family Planning Practices of Rural Community Dwellers in Cross River State, Nigeria. Nigeria Journal of Clinical Practice, 2017; 20: 707-15. https://doi.org/10.4103/njcp.njcp_193_15

8. Gidado, O.S. (2012). Community and individual level factors influencing modern contraceptive use among married women of reproductive age group (15-49) in Nigeria. Thesis, Faculty of Public Health, University of Ibadan. Available at: https://library.adhl.africa/handle/123456789/12176

9. Gilliam ML, Warden M, Goldstein C \& Tapia B (2004). Concerns about contraceptive side effects among young Latinas: a focus group approach. Contraception, 70(4):299-305. https://doi.org/10.1016/j.contraception.2004.04.013

10. Gujarati, D.N. (2004). Basic econometrics, 4th edition, USA: McGraw-Hill Companies, 2004.

11. Hawkins J, Matteson PS and Tabeek ES (1995), A Fertility Control in Fogel, CI and NWoods (Eds.), A Comprehensive Handbook. London, UK, Sage Publishers,

Inc. https://doi.org/10.2147/OAJC.S94826

12. Health Policy Initiatives (HPI), Task Order 1 (2007). Inequalities in the use of family planning and reproductive health services: implications for policies and programs, inequities and barriers to family planning services, Washington D.C. Microsoft Word 
- Inequalities in Use of Family Planning final 2-8-07 bw.doc (healthpolicyplus.com).

13. Kaggwa, E.B., Diop, N., \& Storey, J.D. (2008). The role of individual and community normative factors: a multilevel analysis of contraceptive use among women in union in Mali. International Family Planning Perspectives, 32(2): 79-88. https://doi.org/10.1363/3407908

14. Nigeria Demographic and Health Survey, NDHS (2018). National Population Commission, Abuja, Nigeria. Nigeria Demographic and Health Survey 2018 - Summary Report [SR264] (dhsprogram.com).

15. Odimegwu, C.O., Ojo, M., \& Amd-Siyangande, A. (1997). Regional correlates of choice of contraceptive methods in Nigeria. Korea Journal of Population and Development, 26(1):131-145. Available at: https://www.jstor.org/stable/43783497

16. Orji, E.O., \& Onwudiegwu, U. (2002). Prevalence and determinants of contraceptive practice in a defined Nigerian population. Journal of Obstetrics Gynecology, 22(5):5403. https://doi.org/10.1080/0144361021000003126

17. Oyedokun, A.O. (2007). Determinants of Contraceptive Usage: Lessons from Women in Osun. Asia-Pacific Population Journal, 6(1):25-38.

18. Oye-Adeniran, B.A., Adewole, I.F., Umoh, A.V., Oladokun, A., Ghadegsin, A., Ekanem, E.E., Yusuf, B., Odeyemi, K.A., Iwere, N., \& Mahmoud, P. (2006). Community-based study of contraceptive behaviour in Nigeria. Afr J Reprod Health, 10(2):90-104. PMID: 17217121.

19. Rele, J, R., Kapoor, P.N., \& Khan, M.E. (2019). Determinants and consequences of contraceptive method choice in India. Choosing a Contraceptive, 191-211. https://doi.org/10.4324/9780429042881-10

20. Shrestha, A., Stoeckel, J., \& Tuladhar, J.M. (2000). The KAP-gap in Nepal: reasons for Non-use of contraception among couples with an unmet need for family planning. Asia-Pacific Population Journal, 6(1), 25-38. https://doi.org/10.18356/1b0f170f-en

21. Umoh, A.V., \& Abah, M.G. (2011). Contraception awareness and practice among antenatal attendees in Uyo, Nigeria. Pan African Medical Journal, 10(53). https://doi.org/10.5455/gmj-30-45779

22. USAID/HPI (2007). Achieving Equity for the Poor in Kenya, 2007. Achieving EQUITY for the Poor in Kenya: - Health Policy Initiative (yumpu.com)

23. Westoff, C., \& Cross, A. (2006). The stall in the fertility transition in Kenya, DHS Analytical. The
DHS Program - The Stall in the Fertility Transition in Kenya (English).

24. Westoff, C.F. (2012). Unmet need for modern contraceptive methods-DHS analytical studies 28 . Unmet Need for Modern Contraceptive Methods [AS28] (dhsprogram.com).

25. Westoff, C.F., \& Rodriguez, G. (1995). The mass media and family planning in Kenya. International Family Planning Perspectives, 21(1), 26 - 31. https://doi.org/10.2307/2133602 